\title{
Pathogenetic mechanisms and treatment options for ophthalmic pterygium: Trends and perspectives (Review)
}

\author{
EFSTATHIOS T. DETORAKIS ${ }^{1}$ and DEMETRIOS A. SPANDIDOS ${ }^{2}$ \\ ${ }^{1}$ Department of Ophthalmology, University Hospital of Heraklion; ${ }^{2}$ Laboratory of Virology, \\ Medical School, University of Crete, Heraklion, Crete, Greece
}

Received January 20, 2009; Accepted February 19, 2009

DOI: 10.3892/ijmm_00000149

\begin{abstract}
Pterygium is a fibrovascular lesion of the ocular surface that can display an aggressive clinical behavior and, occasionally, threaten vision. Although there is no consensus on its pathogenesis, recent evidence suggests that it is a proliferative, rather than degenerative condition strongly correlated with exposure to ultraviolet radiation (UVR) of solar light. Molecular genetic alterations reported in association with pterygium include loss of heterozygosity ( $\mathrm{LOH})$, point mutations of proto-oncogenes, such as K-ras and alterations in the expression of tumor suppressor genes, such as p53 or p63. Other findings in pterygium include the frequent detection of HPV DNA, ocular surface changes such as the overexpression of various proteins, including defensins and phospolipases D, as well as the up-regulation of growth factors, such as bFGF or VEGF. Although pterygium management has traditionally involved surgery, often enhanced by the use of antimetabolites, recent advancements in the understanding of molecular and biochemical events underlying pterygium pathogenesis may enable the use of less invasive treatment methods.
\end{abstract}

\section{Contents}

1. Introduction

2. Epidemiology, clinical and histochemical features

3. Pathogenetic theories

4. Treatment options

5. Conclusions and future trends

\section{Introduction}

Despite the fact that its original description dates back to the time of Hippocrates, the ophthalmic pterygium still manages

Correspondence to: Dr Efstathios T. Detorakis, Department of Ophthalmology, University Hospital of Heraklion, 71110 Heraklion, Crete, Greece

E-mail: detorakis@hotmail.com

Key words: pterygium, pathogenesis, ultraviolet radiation, growth factors, cytokines, viral infection, ocular surface surgery, antimetabolites to keep the secrets of its pathogenesis and, more importantly, may still occasionally threaten vision (1). Apparently, the condition has not changed since the ancient times and can be described as a fibrovascular membrane advancing on the corneal surface, often triangular in shape (with the apex towards the corneal centre), sometimes bilateral and usually originating from the nasal bulbar conjunctiva, but also occasionally from the temporal conjuctiva (Fig. 1) $(1,2)$. Numerous theories have so far been proposed to describe its pathogenesis, although none has gained unanimous acceptance $(2,3)$. Pterygium was originally considered an 'ophthalmoheliosis', i.e., a condition closely related to the exposure of the eyes to increased amounts of sunshine which could, through poorly understood mechanisms, result in fibrovascular growth on the ocular surface $(2,4)$. However, during the last decades, several potential mechanisms for pterygium development have been examined, mostly by employing molecular genetic analysis techniques of tissue samples (5-10). Consequently, insights into the pathogenesis of pterygium were gained through the improved understanding of molecular genetic pathways (5-10). The advent of commercially available pharmaceutical agents which could, acting on a molecular level, affect important aspects of pterygium clinical behaviour, such as the angiogenesis or cellular proliferation, opens a promising new therapeutic avenue $(11,12)$. Therefore, future treatment options may be less invasive and more focused on molecular pathogenetic pathways.

\section{Epidemiology, clinical and histochemical features}

The condition is common in the so-called 'pterygium zone' which is defined by a geographical latitude of $40^{\circ}$ north and south of the equator (4). In countries within this area prevalence of up to $22 \%$ in the general population has been reported (2). In countries outside this area (in either northern or southern latitudes) reported prevalence rates usually do not exceed $2 \%$ of the general population and the lesion affects mostly patients with an increased exposure to solar light, such as people working outdoors $(13,14)$. A slightly higher incidence in males is reported which may be attributed to different life-styles between genders (with males spending more time out-doors) in many countries $(13,14)$.

Apart from the triangular shape (often described as having a head, body and tail), pterygium is characterized by its location along the inter-palpebral fissure (along the horizontal 

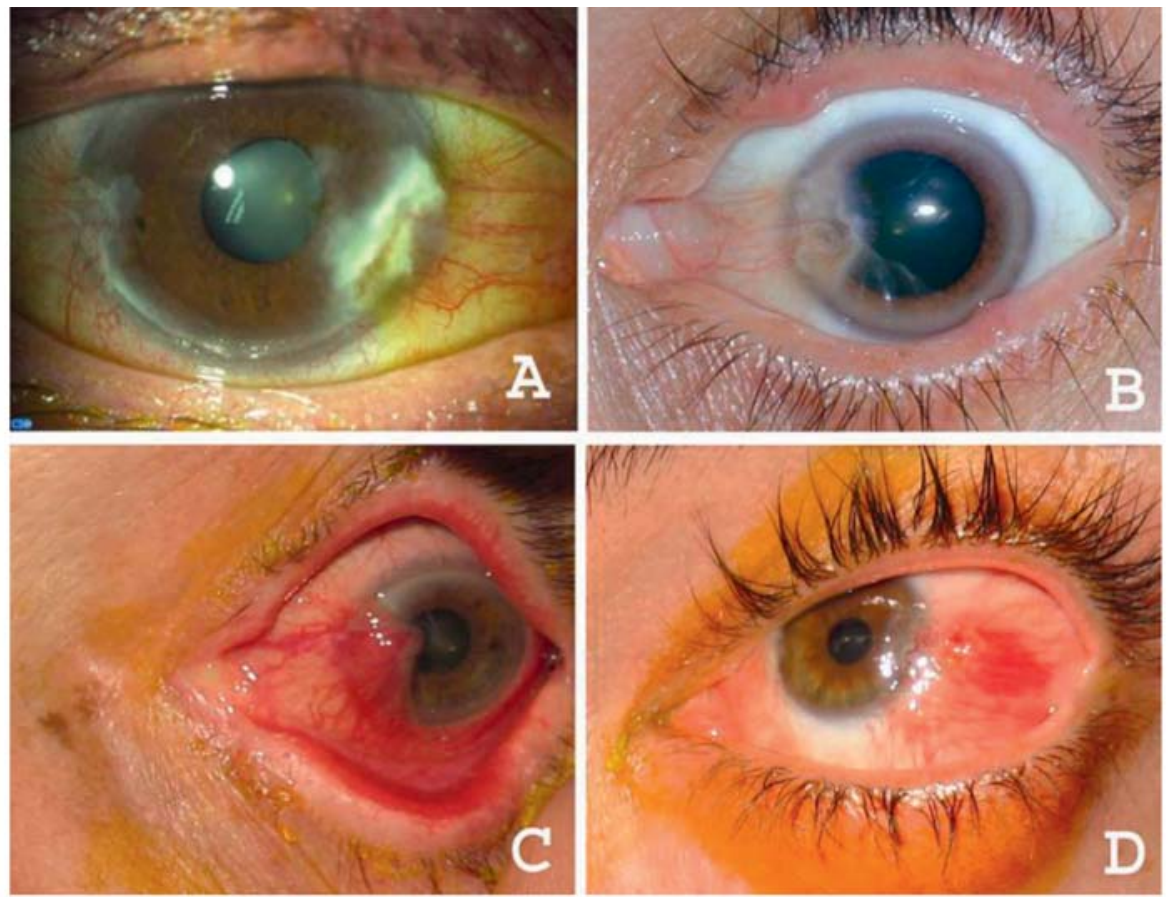

Figure 1. Various forms of pterygium, including simultaneous nasal and temporal pterygium (A), quiescent nasal pterygium (B), inflammatory nasal pterygium (C) and inflammatory temporal pterygium (D).

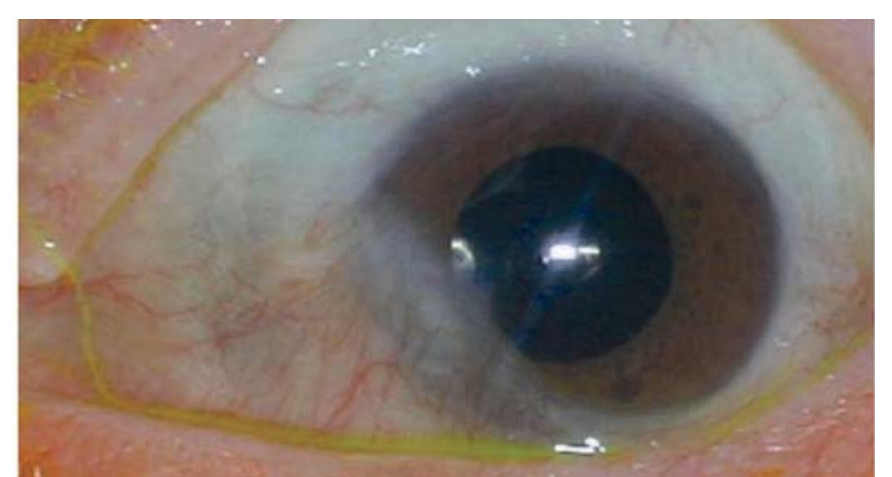

Figure 2. Pseudopterygium developing at the inferior-nasal quadrant of the bulbar conjunctiva following a local acid burn.

axis of cornea, usually nasally but occasionally also temporally or both nasally and temporally, Fig. 1), which was considered an important indication of the role of environmental factors, such as solar light, in its development. In fact, the development of pterygium-like lesions in axes other than the horizontal (pseudo-pterygium) is secondary to traumatic, inflammatory or vascular conditions and, therefore, not true pterygium (Fig. 2). Symptoms associated with pterygium development include chronic ocular surface inflammation, tearing, astigmatism and blurred vision due to optical axis involvement on the corneal surface (6). The natural history of the condition is variable, sometimes characterized by prolonged static periods, often associated with corneal linear iron deposition (Stocker's line) along pterygium head, originating from tear film lactoferin (Fig. 3B) (15). However, progressive growth characterizes the majority of pterygia, especially those affecting younger individuals, often necessitating surgical removal $(16,17)$. Pterygium surgery can result in further clinical manifestations, including symblepharon formation (often affecting ocular motility), corneal clouding and corneal or scleral dellen (Fig. 3) (17,18). Importantly, postoperative recurrence (Fig. 4) is common (described in up to $50 \%$ of cases, depending on the technique employed) and sometimes results in even more aggressive clinical behaviour $(17,18)$.

Histologically, pterygium is characterized by elastotic degeneration of conjunctival substantia propria, with associated eosinophilic or basophilic deposits (19). Degenerated type I and type IV collagen fibers as well as immature elastin fibers (elastin dysplasia) or degenerated elastin fibers (elastin dystrophy) have also been described $(19,20)$. Epithelial changes are variable and include hyperkeratosis, parakeratosis or akanthosis (21). Fibroblasts lying at the anterior corneal stroma (underneath Bowman's membrane) may become activated by ultraviolet radiation and may cause Bowman's membrane rupture resulting in the firm adherence of pterygium on underlying corneal stroma (22). On the contrary, the presence of Tenon's capsule prevents the adherence of the episcleral portion of pterygium on the underlying sclera $(21,22)$. From a histochemical standpoint, abnormal forms of mucopolysaccharides, often with increased amounts of neutral sugars and sialic acid, are reported in pterygia, together with higher levels of specific amino acids, such as praline, compared with normal conjuctiva (23-25).

\section{Pathogenetic theories}

Early pathogenetic concepts. The association between pterygium development and specific lifestyles, such as outdoors working or exposure to sunshine or dust led to the idea that chronic ocular surface irritation by such environmental factors might be the cause of the condition $(2,4)$. It was also proposed that pterygium arises from other sunshine-related conditions, 

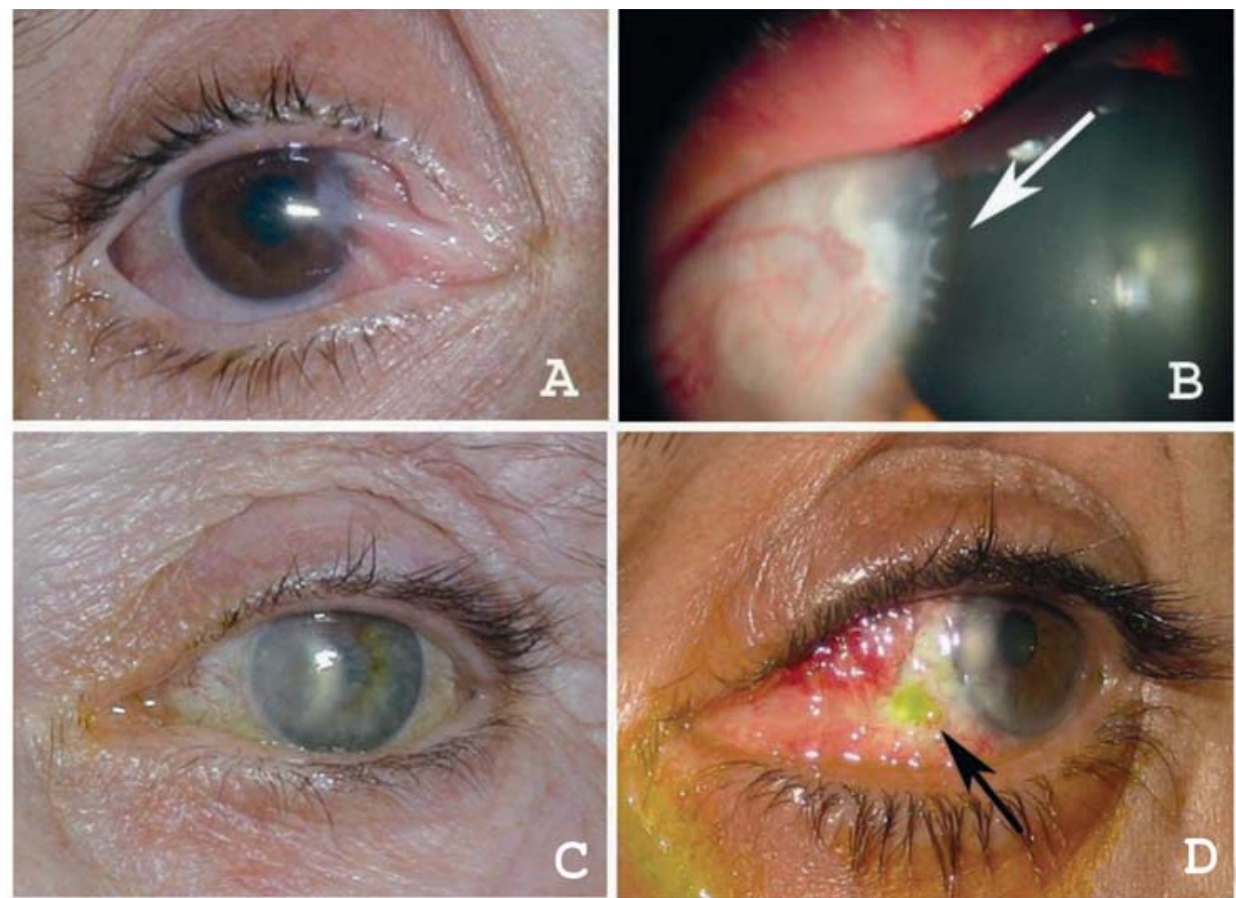

Figure 3. Aspects of pterygium clinical behaviour, including the postoperative symblepharon formation (A), Stocker's line along pterygium head (B), postoperative corneal opacity at the site of pterygium bed (C) and scleral dellen with impending perforation following pterygium removal with adjuvant MMC application (D).

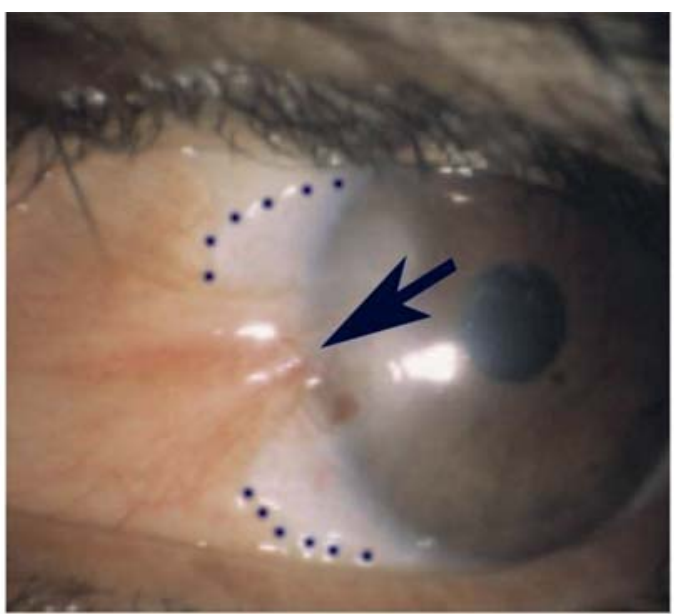

Figure 4. Pterygium postoperative recurrence as a fibrovascular band (arrow) crossing the epithelialized area of bare sclera created at the initial pterygium removal (blue dots) and advancing on the corneal surface.

such as the pingueculum (Fig. 5), a hyalinized nodule appearing at the sclerocorneal limbus (26). Pingueculum has no growth potential per se but may become inflamed and can evolve into a true pterygium (26). The frequently observed conjunctival vascular congestion in the area of pterygium body has lead to the suggestion that medial rectus activity, which underlies the area of pterygium growth nasally, can cause blood flow disturbance potentially associated with pterygium growth $(2,4)$. Early reports have even involved alterations in lacrimal composition or flow (pooling of tears) or the unspecified local effects of lactic acid secreted by periocular sweat glands (27-29).

Concepts of inheritance. Early reports mentioned the possibility of an autosomal dominant pattern of inheritance, based on

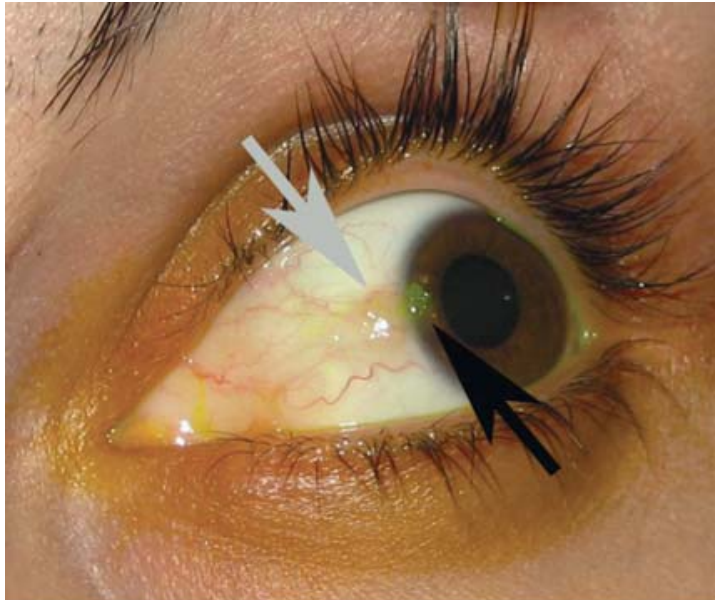

Figure 5. Pingueculum (grey arrow) is a lesion of the sclerocorneal limbus that differs from pterygium in that it does not grow on the corneal surface. However, it may become inflamed or be associated with local corneal dellen (black arrow) and, according to one theory, may be a precursor to pterygium development.

cases with familial occurrence of pterygium (2). However, it could not be verified whether the pterygium itself is inherited, as an independent trait, or if the affected individuals shared an increased susceptibility to the oculodermal effects of solar light $(6,7,30)$. The detection of potential tumor suppressor gene involvement in pterygium has raised the possibility of a 'two hit' mechanism (Knudson's theory) in its pathogenesis $(7,30)$. According to this hypothesis, the 'first hit' in the process of a tumor suppressor gene deactivation may be inherited whereas the 'second hit' may be inflicted by environmental factors, such as a viral infection or UVR (30). However, the fact that no specific genetic locus has so far been associated 


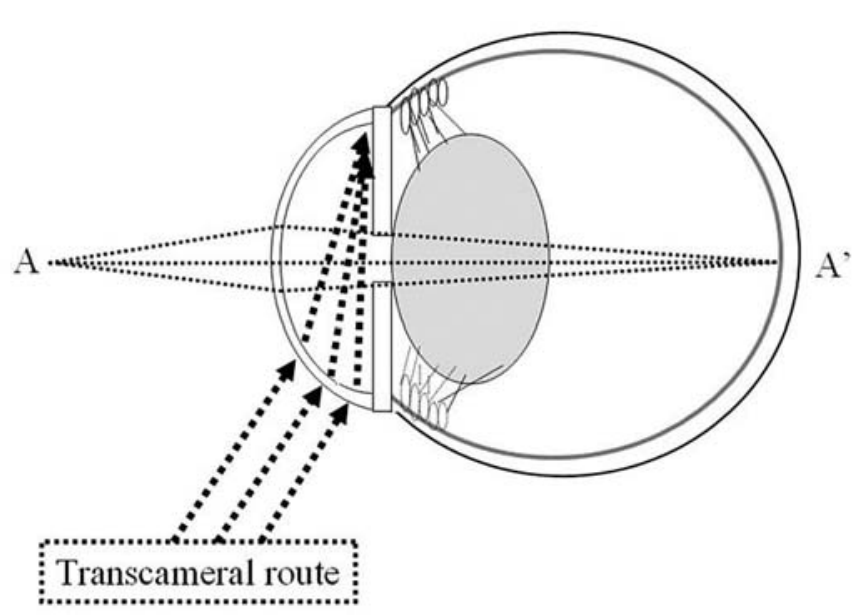

Figure 6. Transcameral light focusing on the nasal limbus may expose limbal basal stem cells to increased amounts of UVR and be associated with molecular genetic alterations to these cells, eventually leading to pterygium formation.

with pterygium development implies that further research in the area of genetic susceptibility for pterygium is required before safer conclusions on this issue are reached.

The role of $U V R$. The strong epidemiological correlation between pterygium development and exposure to sunshine has lead to the assumption that some parts of the solar radiation may have a direct pathogenetic role $(2,4)$. Periorbital architecture, including the presence of the superior orbital rim, the presence of eyebrows and the nasal prominence imply that the eyes are relatively protected from direct light exposure from above $(2,4)$. On the other hand, the eyes are relatively unprotected from light scattered from below or laterally (albedo) (4). Early reports raised the possibility that solar light exposure acted in combination with exposure to dust or sand, thus leading to chronic ocular surface inflammation (2). However, the detection of high pterygium prevalence in sailors or fishermen, who lived in environments devoid of dust but instead were exposed to increased amounts of scattered light from reflective surfaces such as the sea surface, pointed towards an albedo involvement in pterygium formation (31). In fact, it was suggested that scattered light might follow alternative (transcameral) optical paths when entering the eye, thus hitting limbal stem cells from their inner surface (Fig. 6) (4). Some studies have even suggested that the nasal location of pterygium is an indication of the pathogenetic role of solar light, since light may be reflected onto the nasal sclerocorneal limbus from the lateral nasal wall whereas the nasal bulbar conjunctival is more exposed to sunshine since brow hair is shorter nasally than temporally (Fig. 7) (4). The effects of UVR-A and UVR-B (290-400 nm) are considered particulary detrimental (32). At a molecular level, UVR is associated with the creation of active free radicals which attack and deactivate various macromolecules (33). Free radicals may in turn be deactivated by tear film proteins, including lactoferrin (34). The presence of Stocker's line along the head of pterygia lacking growth potential, as previously mentioned, may represent abnormal local iron metabolism along the advancing head of pterygium. Iron

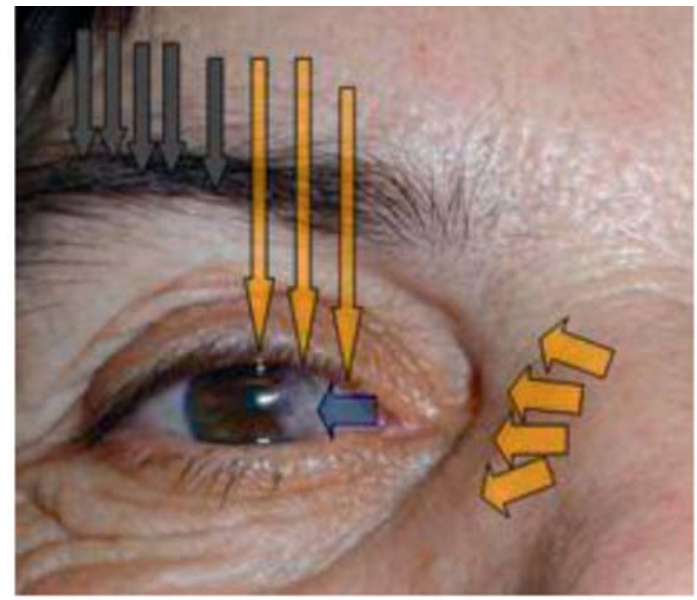

Figure 7. Light reflected from the lateral aspect of the nose on the corneal limbus as well as incident light falling on nasal limbus due to the short length of brow hair nasally (yellow arrows) may contribute to the formation of pterygium nasally (blue arrow). On the other hand, the temporal limbus is relatively protected from incident light due to the longer length of brow hair temporally (grey arrows).

itself may be associated with increased free radical formation through biochemical (Fenton) reactions (35).

Ocular surface changes and pterygium. Previous studies have reported an association between pterygium and dry eye changes, such as reduced tear-film break-up time (BUT) $(28,36,37)$. Such findings indicated that pterygium may be a manifestation of a generalized ocular surface dysfunction, including a chronic inflammatory reaction (38). In accordance with these reports, an up-regulation of the expression of human $\alpha$-defensins and S100 A8 and A9 in tear fluids of pterygium patients provides additional indications for a connection between pterygium and chronic ocular surface inflammation (38). Another study has reported the up-regulation of phospholipase D (PLD) types 2, 3 and 4 in pterygium, compared with normal conjunctiva (39). PLD are involved in various processes, including inflammation, cell differentiation, apoptosis and wound healing and the detection of PLD alterations in pterygium supports their potential role in pterygium pathogenesis (39).

Oxidative stress. Increased UVR-associated oxidative stress has been reported in pterygium, compared with normal conjunctiva, leading to the induction of proteins, such as survivin (40). The latter has been correlated with DNA oxidation and down-regulation of p53 (40). Interestingly, it has been suggested that the presence of iron deposits along the corneal head of pterygium may indicate oxidative stress affecting local epithelial cells and resulting in disturbed iron homeostasis (35). The topical use of antioxidants as an adjuvant treatment option for pterygium would thus seem logical and should be investigated in future research projects.

Molecular genetic alterations. Previous studies have detected both loss of heterozygosity $(\mathrm{LOH})$ and microsatellite instability (MI) in pterygium $(5,6)$. However, the association of LOH with pterygium was found much stronger, compared with the 
respective association with $\mathrm{MI}$ implying that the involvement of the latter in pterygium etiopathogenesis is less important (6). On the contrary, the close association of $\mathrm{LOH}$ with pterygium points towards an involvement of tumor suppressor genes in its development $(6,30)$. Indeed, p53 levels have been reported increased in pterygia by several previous studies although other studies have not confirmed such findings $(3,41,42)$. The up-regulation of p53 expression in pterygia may merely reflect increased exposure to UVR, since the wild-type of p53 is known to increase in normal tissues in response to DNA damaging agents, such as UVR $(3,43)$. The generally employed methodology to measure $p 53$ tissue levels (antibodies against p53 protein) cannot distinguish between wild-type and mutant forms (3). Wild-type $p 53$ is critical in causing cell-cycle arrest in rapidly proliferating cells (3). However, its action depends on various factors, such as the levels of acetylation or phosphorylation $(44,45)$. Interestingly, the levels of p53 expression in pterygia have been found to differ between epithelial layers being higher in basal cells, compared to more superficial layers $(3,46,47)$. This finding could reflect increased exposure to UVR according to the proposed theory of transcameral exposure of limbal basal (stem) cells to solar light. Recurrent pterygia also display reduced amounts or total lack of $p 53$ expression which may be an indication that the epithelial cells escape the p53-dependent cell cycle checkpoint (3). Alterations in proteins with functional and structural homology to $p 53$, such as $p 63$ and $p 73$, have also been detected in pteygium $(48,49)$. These proteins are involved in cellular differentiation and alterations in their genes have been linked to various systemic and ocular abnormalities $(3,48,49)$. Interestingly, $p 63$ expression in pterygium resembles the patterns seen in normal limbus (expressed mainly at the basal epithelial layers) and differs from the pattern seen in normal cornea (almost total absence of p63 expression), a finding supporting the possibility of limbal origin of pterygium (50).

Apart from TSGs, proto-oncogene (POG) sequences may also be affected by UVR $(51,52)$. Mutations in genes of the ras family POGs, including Harvey-Ras (H-ras), Kirsten-Ras (K-ras) and Neuroblastoma-ras (N-ras), have been detected in cultured cells of mouse skin tumors following exposure to near-UVR (51) and are also frequently detected in human neoplastic conditions of sun-exposed body areas, such as cutaneous melanomas (52). Such mutations may convert these genes into active oncogenes (53). Restriction fragment length polymorphism (RFLP) and sequencing analysis of primary and recurrent pterygia has revealed $\mathrm{K}$-ras mutations at codon 12 in $10 \%$ of pterygia (a transition from GGT-glycine to GTT-valine, in all cases) and an absence of such mutation in respective phenotypically normal conjunctival specimens, as well as peripheral blood samples (8). A lack of mutations at codons 12 and 13 for $\mathrm{H}$-ras and $\mathrm{N}$-ras was also reported (8). Importantly, mutations at codon 12 of K-ras was correlated with postoperative recurrence and young age, implying that such alterations have a direct link with the clinical profile of pterygium (8). The involvement of TSG and POG in pterygium implies that pterygium shares some similarities with neoplastic conditions $(8,30)$. Many neoplasias and immortalized cell lines also display up-regulation of telomerase, a ribonucleoprotein participating in cell division by blocking telomere shortening $(3,54,55)$. Telomerase is not expressed in most adult human tissues, including normal conjuctiva $(3,54,55)$. Telomerase is however expressed in pterygium, a finding attributed to neoplastic features of the lesion or, alternatively, to induction by UVR $(3,54,55)$.

Another interesting aspect of the molecular genetic profile of pterygium is the altered apoptotic potential of its epithelial cells (3). Previous studies have found that UVR induces apoptosis to normal corneal epithelium $(56,57)$. However, epithelium in pterygium in possibly resistant to UVR-mediated apoptosis (3). It is likely that this finding is due to a disturbed balance between pro-apoptotic proteins (such as bax) and anti-apoptotic proteins (such as bcl-2) in the epithelium of pterygium, in favour of the latter (58). Again, differences in the apoptotic status between different epithelial cell layers have been detected with apoptosis remaining active at the basal epithelium of pterygium but not at more superficial epithelial layers $(3,59)$.

The role of genetically altered limbal stem cells. In their 1994 study, Kwok and Coroneo proposed that the initial biologic event in pterygium pathogenesis may be a genetic alteration of limbal stem cells, due to chronic UVR exposure (60). They postulated that a breakdown of the corneoscleral limbal barrier results in subsequent conjunctivalization of the cornea resulting in pterygium (60). They also suggested that the triangular (wing-like) shape of pterygium may in fact be explained by the limbal origin theory since a disrupted balance between the populations of epithelial cells in cornea and conjunctiva could, according to data from animal models, result in advancement of conjunctival epithelium on the corneal surface (60). Further studies in this area, employing immunohistochemistry, found that, in contrast to normal conjunctival, limbal, and corneal cells which immunostain primarily for matrix metalloproteinase-I (MMP-I), limbal basal epithelial cells (pterygium cells) immunostain for multiple types of MMPs (MMP-1, MMP-2, MMP-3, MMP-9, membrane type 1-MMP, and membrane type 2-MMP) (3). According to these results, the altered MMP expression of limbal basal epithelial cells (pterygium cells) enables them to invade and dissolute Bowman's layer leading to firm adhesion of the lesion on the corneal surface $(3,61)$.

Viral involvement. Although early reports mentioned the possibility of an infectious origin of pterygium, evidence on this issue was not conclusive (4). However, the advent of PCR as a research tool enabled the detailed investigation for viral DNA in samples of both pterygia and normal conjunctiva (7). The presence of viruses known to cause oculodermal infections, such as herpes simplex virus (HSV), and human papilloma virus (HPV), was examined $(7,62,63)$. Results from several studies point towards the involvement of HPV in pterygium although large regional and racial differences have been reported $(62,63)$.

Growth factors and cytokines. UVR-mediated genetic trauma may affect the expression of various cytokines, growth factors and growth factor receptors (3). The presence or altered expression of such factors in pterygium has been evaluated by previous studies using various methods including immuno- 
histochemistry, or ELISA (9). Many such factors also participate in normal corneal healing and their altered expression in pterygium may indicate a response to ocular surface damage inflicted by the lesion (3). UVR-inducible cytokines include the interleukin-1 (IL-1) system, acting in concert with tumor necrosis factor $\alpha(\mathrm{TNF} \alpha)$ it leads corneal keratocytes to adopt a repair phenotype $(64,65)$, the IL-6 (it promotes epithelial cell migration through the induction of integrin receptors) $(66,67)$ and IL-8 (displays mitogenic and angiogenetic activity) $(68,69)$. Growth factors involved in pterygium according to previous reports include the epidermal growth factor (EGF) and heparin-binding EGF (HB-EGF), vascular endothelial growth factor (VEGF), basic fibroblast growth factor (bFGF), platelet-derived growth factor (PDGF), transforming growth factor- $\beta$ (TGF- $\beta$ ) and insulin-like growth factor binding proteins (IGF-BP) (3). VEGF is involved in angiogenesis and is produced by corneal fibroblasts in response to inflammation or other noxious stimuli, including UVR (70). VEGF has been detected in increased amounts in pterygium epithelium, compared with normal conjunctiva by studies employing immunohistochemistry (71). These results were confirmed by RT-PCR assays also revealing a correlation between VEGF expression and post-operative recurrence (own unpublished data). bFGF is involved in the corneal healing process as well as neovascularization and is also overexpressed in cultured fibroblasts from pterygia $(3,9,72)$. Again, RT-PCR assays showed increased bFGF expression in pterygium, compared with normal conjunctiva, a finding possibly reflecting UVRmediated induction (own unpublished data).

\section{Treatment options}

Surgical excision techniques. Early pterygium removal included simple excision (detachment) of pterygium head from the anterior corneal surface $(16,73)$. However, the realization of the potential for recurrence, often more aggressive clinically than the original lesion, soon lead to modifications of simple excision $(16,74)$. The 'bare sclera' technique involved the removal of the lesion and peri-limbal conjunctiva with suturing of the remaining conjunctival rim onto the bare scleral surface at a variable distance from sclerocorneal limbus (Fig. 8A) (75). The rationale for the 'bare sclera' technique was that the area left uncovered would be epithelialized from epithelial cells from the anchored conjunctival rim which could then act as a barrier against pterygium re-growth from pathological tissue remnants inevitably left in situ $(16,75)$. However, up to $50 \%$ of recurrence rate following a successful 'bare sclera' pterygium removal have been described (16).

The understanding of the important role of normal conjunctiva in blocking pterygium re-growth on the corneal surface was the basis for further modifications of the initial technique which in fact departed from the 'bare sclera' idea $(16,74)$. These included conjunctival flap transposition, i.e., the formation of a mobile conjunctival flap, either superiorly or inferiorly to the pterygium bed, which could then be transposed onto the area previously occupied by pterygium, thus providing the normal tissue blockage against pterygium recurrence from more peripheral sites (Fig. 8B and C) $(76,77)$. Instead of the conjunctival flap, a free conjunctival
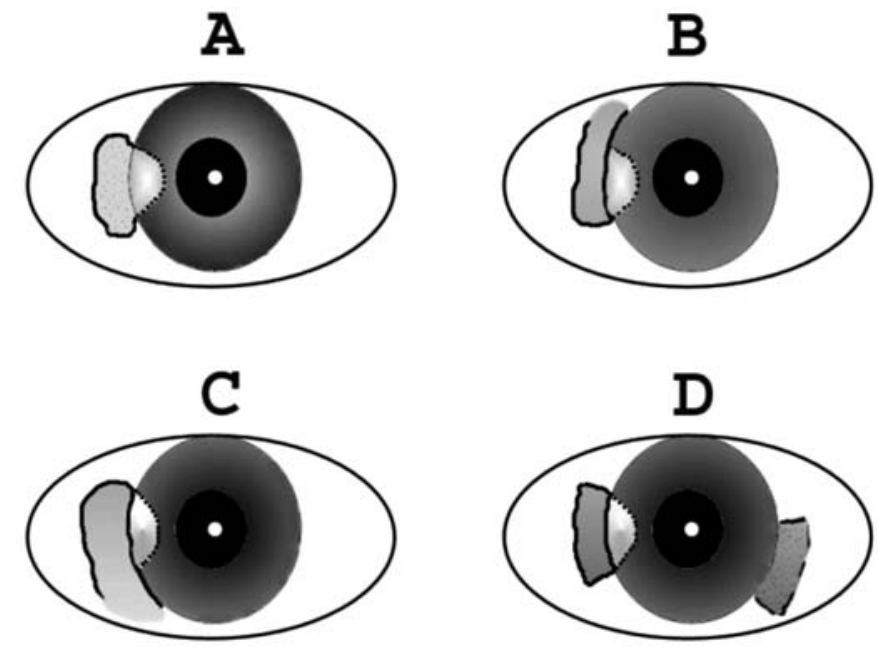

Figure 8. Techniques of pterygium excision include bare sclera removal (A), the creation of advancement conjunctival flaps from superior (B) or inferior (C), bulbar conjunctiva to cover the pterygium bed as well as the creation of a free conjunctival graft, often from the inferior-temporal bulbar conjunctiva, which also contains normal limbal stem cells (D).

graft may be even more advantageous towards this goal because it not only covers the pterygium bed with normal tissue but also can potentially provide a population of normal stem cells positioned onto the sclerocorneal limbal area originally associated with pterygium (Fig. 8D) $(78,79)$. In cases with very large conjunctival defects created following pterygium excision, or if a proper autologous conjunctival graft cannot be harvested, an alternative technique is the use of preserved amniotic membrane, which is readily commercially available and provides an excellent substrate for epithelial regrowth (80). The use of more sophisticated conjunctival surgery is associated with considerably lower recurrence rates, often less than $10 \%(16,78)$. Other modalities for pterygium removal, such as ablation with excimer laser, have not gained widespread acceptance, although excimer laser may have a role in smoothening corneal surface irregularities caused by pterygium $(81,82)$. However, lamellar karatoplasty may also be required, especially in cases of recurrent pterygia with firm adhesion to the corneal stroma (83).

The role of antimetabolites. The fear of an aggressive recurrence always follows pterygium excision, no matter how elegantly primary surgery has been performed. This is why surgery is often combined with adjuvant therapies such as antimetabolites e.g. mitomycin-C (MMC) $(16,78)$. The latter is an antibiotic, a product of streptomyces caesiptosus, capable of alkylating DNA double helix and blocking both transcription and translation $(84,85)$. Thus MMC is also a potent antimetabolite used in suppressing tumor cells $(84,85)$. In the case of pterygium surgery MMC is used in concentrations of $0.2-0.4 \mathrm{mg} / \mathrm{ml}$ applied episclerally for various intervals (usually not more than $2 \mathrm{~min}$ ) (84). The recurrence rate with the adjunctive intraoperative use of MMC is reported to be $<10 \%(16,78,86)$. Apart from the intraoperative use, MMC has also been used as postoperative eye drops $(16,87)$. Other agents include the alkylating agent Thiotepa (N,N'N'triethylenethiophosphoramide), used in concentrations of 
1:2000, either postoperatively or as eye drops (16) and 5-fluorouracil (5-FU), a pyrimidine analogue used either intraoperatively or as postoperative subconjunctival injections $(16,88)$.

Although very effective in reducing recurrence rates, antimetabolite use is, nevertheless, associated with serious and potentially sight-threatening complications, such as delayed healing or even scleral melt (Fig. 2), sometimes threatening vision or requiring further surgery for their management (16). The thin or necrotic sclera resulting from antimetabolites may also be treated with the use of hyperbaric oxygen which induces hyperoxia, angiogenesis and episcleral fibroblast proliferation (89).

$\beta$-irradiation. Historically, irradiation has been one of the first attempts of modern surgery to suppress the potential for recurrence in pterygium management $(90,91)$. $\beta$-irradiation, delivered through strontium-/yttrium-90 sources, effectively reduces cellular populations responsible for pterygium recurrence (92). However, its use is not innocuous and may be associated with serious complications, including visionthreatening endophthalmitis (16).

Growth factor inhibitors. Anti-VEGF monoclonal antibodies have become widely available in ophthalmic practice mainly because of their success in suppressing various forms of intraocular neovascular growth, such as exudative age-related macular degeneration and sub-retinal neovascular membranes, proliferative diabetic retinopathy, or neovascular glaucoma (93). Such factors include Pegaptanib (Macugen, Pfizer), an oligonucleotide aptamer that binds exclusively to the 165 amino acid isoform of VEGF, and recombinant monoclonal antibody Bevacizumab (Avastin, Genentech) as well as its fragment Ranibizumab (Lucentis, Genentech), both directed against VEGF (93). Previous studies have already evaluated the potential use of Bevacizumab in pterygium management $(11,12)$. However, Bevacizumab is also associated with potential serious side effects, including significant cardiovascular toxicity (93). The study of VEGF expression in individual lesions may therefore allow for selective Bevacizumab or other anti-VEGF administration, potentially reducing the risk of recurrence or aggressive clinical behaviour without taking unnecessary systemic risks.

\section{Conclusions and future trends}

Ophthalmic pterygium continues to puzzle doctors, affecting large numbers of patients in many parts of the world. Nevertheless, research with modern molecular techniques has lead to more accurate and detailed information on its origin and growth mechanisms. It is likely that UVR induces ocular surface changes especially affecting stem cells at the corneoscleral limbus. Such changes may be potentially enhanced by the action of other environmental factors, such as HPV infection or oxidative stress. At a molecular level, findings include alterations in the expression of tumor suppressor genes, such as p53, the induction of MMPs as well as alterations in the expression of various growth factors, including VEGFA and bFGF. At a histological level, Bowman's membrane damage, fibrovascular growth as well as elastotic degeneration of various connective tissue elements predominate. Until recently, surgery was the only feasible option of pterygium treatment, in the form of various conjunctival plastic procedures usually enhanced with adjunctive modalities, such as antimetabolites. However, apart from being invasive and associated with a variety of potentially serious complications, surgery often results in a more aggressive clinical behaviour of pterygium. The advent of commercially available antiVEGF has already been explored by preliminary studies. Apparently however, pterygia differ significantly in the profile of cytokine/growth factor alterations they display. The individualized examination of each lesion may enable a customized treatment strategy, according to its molecular profile, thus reducing risks from invasive treatment methods and at the same time increasing success rates.

\section{References}

1. Duke-Elder S: System of ophthalmology. In: Diseases of the Outer Eye. Vol 8. Mosby, St. Louis, MO, pp573-574, 1965.

2. Hilgers J: Pterygium: its incidence, heredity and etiology. Am J Ophthalmol 50: 635-644, 1960.

3. Di Girolamo N, Chui J, Coroneo MT and Wakefield D: Pathogenesis of pterygia: role of cytokines, growth factors, and matrix metalloproteinases. Prog Retin Eye Res 23: 195-228, 2004.

4. Coroneo MT: Pterygium as an early indicator of ultraviolet insolation: a hypothesis. Br J Ophthalmol 77: 734-739, 1993.

5. Spandidos DA, Sourvinos G, Kiaris H and Tsamparlakis J: Microsatellite instability and loss of heterozygosity in human pterygia. Br J Ophthalmol 81: 493-496, 1997.

6. Detorakis ET, Sourvinos G, Tsamparlakis J and Spandidos DA: Evaluation of loss of heterozygosity and microsatellite instability in human pterygium: clinical correlations. Br J Ophthalmol 82: 1324-1328, 1998.

7. Detorakis ET, Sourvinos G and Spandidos DA: Detection of herpes simplex virus and human papilloma virus in ophthalmic pterygium. Cornea 20: 164-167, 2001.

8. Detorakis ET, Zafiropoulos A, Arvanitis DA and Spandidos DA: Detection of point mutations at codon 12 of Ki-ras in ophthalmic pterygium. Eye 19: 210-214, 2005.

9. Kria L, Ohira A and Amemiya T: Growth factors in cultured pterygium fibroblasts: immunohistochemical and ELISA analysis. Graefes Arch Clin Exp Ophthalmol 236: 702-708, 1998.

10. Marcovich AL, Morad Y, Sandbank J, Huszar M, Rosner M, Pollack A, Herbert M and Bar-Dayan Y: Angiogenesis in pterygium: morphometric and immunohistochemical study. Curr Eye Res 25: 17-22, 2002.

11. Hosseini H, Nejabat M and Khalili MR: Bevacizumab (Avastin) as a potential novel adjunct in the management of pterygia. Med Hypotheses 69: 925-927, 2007.

12. Bahar I, Kaiserman I, McAllum P, Rootman D and Slomovic A: Subconjunctival bevacizumab injection for corneal neovascularization in recurrent pterygium. Curr Eye Res 33: 23-28, 2008.

13. Forsius $\mathrm{H}$ and Eriksson A: Pterygium and its relation to arcus senilis, pinguecula and other similar conditions. Acta Ophthalmol 40: $402,1962$.

14. Mackenzie FD, Hirst LW, Battistutta D and Green A: Risk analysis in the development of pterygia. Ophthalmology 99: 1056-1061, 1992.

15. Hansen A and Norn M: Astigmatism and surface phenomena in pterygium. Acta Ophthalmol 58: 174-181, 1980.

16. Hirst LW: The treatment of pterygium. Surv Ophthalmol 48: 145-180, 2003.

17. Díaz L, Villegas VM, Emanuelli A and Izquierdo NJ: Efficacy and safety of intraoperative mitomycin $\mathrm{C}$ as adjunct therapy for pterygium surgery. Cornea 27: 1119-1121, 2008.

18. Tarr KH and Constable IJ: Late complications of pterygium treatment. Br J Ophthalmol 64: 496-505, 1980.

19. Austin P, Jakobiec FA and Iwamoto T: Elastodysplasia and elastodystrophy as the pathologic bases of ocular pterygia and pinguecula. Ophthalmology 90: 96-109, 1983.

20. Hogan MJ and Alvarado J: Pterygium and pinguecula: electron microscopic study. Arch Ophthalmol 78: 174-186, 1967. 
21. Spencer WH and Zimmerman LE: Conjunctiva. In: Ophthalmic Pathology. Spencer WH (ed). Vol 1. W.B. Saunders, Philadelphia, PA, pp174-175, 1985 .

22. Dake Y, Mukae R, Soda Y, Kaneko M and Amemiya T: Immunohistochemical localization of collagen types I, II, III, and IV in pterygium tissues. Acta Histochem 87: 71-74, 1989

23. Kawano K, Uehara F and Ohba N: Lectin-cytochemical study on epithelial mucus glycoprotein of conjunctiva and pterygium. Exp Eye Res 47: 43-51, 1988.

24. Kaneko M, Takaku I and Katsura N: Glycosaminoglycans in pterygium tissues and normal conjunctiva. Jpn J Ophthalmol 30 $165-173,1986$

25. Kaneko M: Proteoglycans from pterygium tissues. Ophthalmic Res 19: 170-177, 1987.

26. Jaros PA and De Luise VP: Pingueculae and pterygia. Surv Ophthalmol 33: 41-49, 1988.

27. Kadayifcilar SC, Orhan M and Irkec M: Tear functions in patients with pterygium. Acta Ophthalmol 76: 176-179, 1998.

28. Biender B, Biger Y, Rothkoff L and Sachs U: Pterygium and basic tear secretion. Ann Ophthalmol 11: 1235-1236, 1979

29. Miller D: Light and the cornea and conjunctiva. In: Clinical Light Damage to the Eye. Miller D, et al (eds). Springer Verlag, New York, NY, pp55-63, 1987.

30. Detorakis ET, Drakonaki EE and Spandidos DA: Molecular genetic alterations and viral presence in ophthalmic pterygium (Review). Int J Mol Med 6: 35-41, 2000.

31. Diponegoro RMA and Mulock-Houwer AW: A statistical contribution to the study of the aetiology of pterygium. Folia Ophthalmol Orient 2: 195-210, 1936

32. Taylor HR, West SK, Rosenthal FS, Munoz B, Newland HS and Emmett EA: Corneal changes associated with chronic UV irradiation. Arch Ophthalmol 107: 1481-1484, 1989.

33. Said T, Dutot M, Martin C, Beaudeux JL, Boucher C, Enee E, Baudouin C, Warnet JM and Rat P: Cytoprotective effect against UV-induced DNA damage and oxidative stress: role of new biological UV filter. Eur J Pharm Sci 30: 203-210, 2007.

34. Weinberg ED: The therapeutic potential of lactoferrin. Expert Opin Investig Drugs 12: 841-851, 2003.

35. Loh A, Hadziahmetovic M and Dunaief JL: Iron homeostasis and eye disease. Biochim Biophys Acta (In press).

36. Chaidaroon $\mathrm{W}$ and Pongmoragot N: Basic tear secretion measurement in pterygium. J Med Assoc Thai 86: 348-352, 2003.

37. Rajiv, Mithal S and Sood AK: Pterygium and dry eye - a clinical correlation. Indian J Ophthalmol 39: 15-16, 1991.

38. Zhou L, Beuerman RW, Ang LP, Chan CM, Li SF, Chew FT and Tan DT: Elevation of human \{alpha\}-defensins and S100 calcium binding protein A8 and A9 in tear fluid of pterygium patients. Invest Ophthalmol Vis Sci (In press).

39. Tong L, Li J, Chew J, Tan D and Beuerman R: Phospholipase D in the human ocular surface and in pterygium. Cornea 27: 693-698, 2008

40. Maxia C, Perra MT, Demurtas P, Minerba L, Murtas D, Piras F, Corbu A, Gotuzzo DC, Cabrera RG, Ribatti D and Sirigu P: Expression of survivin protein in pterygium and relationship with oxidative DNA damage. J Cell Mol Med 12: 2372-2380, 2008

41. Dushku N and Reid TW: p53 expression in altered limbal basal cells of pingueculae, pterygia, and limbal tumors. Curr Eye Res 16: 1179-1192, 1997.

42. Shimmura S, Ishioka M, Hanada K, Shimazaki J and Tsubota K: Telomerase activity and p53 expression in pterygia. Invest Ophthalmol Vis Sci 41: 1364-1369, 2000

43. De Winter S, Vink AA, Roza L and Pavel S: Solar-simulated skin adaptation and its effect on subsequent UV-induced epidermal DNA damage. J Invest Dermatol 117: 678-682, 2001.

44. Ashcroft $\mathrm{M}$ and Vousden KH: Regulation of p53 stability. Oncogene 18: 7637-7643, 1999.

45. Lakin ND and Jackson SP: Regulation of p53 in response to DNA damage. Oncogene 18: 7644-7655, 1999.

46. Tan DT, Lim AS, Goh HS and Smith DR: Abnormal expression of the p53 tumor suppressor gene in the conjunctiva of patients with pterygium. Am J Ophthalmol 123: 404-405, 1997.

47. Weinstein O, Rosenthal G, Zirkin H, Monos T, Lifshitz T and Argov S: Overexpression of p53 tumor suppressor gene in pterygia. Eye 16: 619-621, 2002

48. Kaghad M, Bonnet H, Yang A, Creancier L, Biscan JC, Valent A, Minty A, Chalon P, Lelias JM, Dumont X, Ferrara P, McKeon F and Caput D: Monoallelically expressed gene related to p53 at $1 \mathrm{p} 36$, a region frequently deleted in neuroblastoma and other human cancers. Cell 90: 809-819, 1997.
49. Yang A, Kaghad M, Wang Y, Gillett E, Fleming MD, Dotsch V, Andrews NC, Caput D and McKeon F: p63, a p53 homolog at 3q27-29, encodes multiple products with transactivating, deathinducing, and dominant-negative activities. Mol Cell 2: 305-316, 1998.

50. Di Girolamo N, Coroneo MT and Wakefield D: UVB-elicited induction of MMP-1 expression in human ocular surface epithelial cells is mediated through the ERK1/2 MAPK-dependent pathway. Invest Ophthalmol Vis Sci 44: 4705-4714, 2003

51. Dushku N and Reid TW: Immunohistochemical evidence that human pterygia originate from an invasion of vimentin-expressing altered epithelial basal cells. Curr Eye Res 13: 473-481, 1994.

52. Nishigori C, Wang S, Miyakoshi J, Sato M, Tsukada T, Yagi T, Imamura $\mathrm{S}$ and Takebe $\mathrm{H}$ : Mutations in ras genes in cells cultured from mouse skin tumors induced by ultraviolet irradiation. Proc Natl Acad Sci USA 19: 7189-7193, 1994.

53. El-Shabrawi Y, Radner H, Muellner K, Langmann G and Hoefler G: The role of UV-radiation in the development of conjunctival malignant melanoma. Acta Ophthalmol Scand 77: 31-32, 1999.

54. Forsyth NR, Wright WE and Shay JW: Telomerase and differentiation in multicellular organisms: turn it off, turn it on, and turn it off again. Differentiation 69: 188-197, 2002.

55. Park TK and Jin KH: Telomerase activity in pterygeal and normal conjunctival epithelium. Korean J Ophthalmol 14: 85-89, 2000.

56. Podskochy A, Gan L and Fagerholm P: Apoptosis in UV exposed rabbit corneas. Cornea 19: 99-103, 2000

57. Ren $\mathrm{H}$ and Wilson G: The effect of ultraviolet-B irradiation on the cell shedding rate of the corneal epithelium. Acta Ophthalmol 72: 447-452, 1994

58. Tan DT, Tang WY, Liu YP, Goh HS and Smith DR: Apoptosis and apoptosis related gene expression in normal conjunctiva and pterygium. Br J Ophthalmol 84: 212-216, 2000.

59. Podskochy A and Fagerholm P: Repeated UVR exposures cause keratocyte resistance to apoptosis and hyaluronan accumulation in the rabbit cornea. Acta Ophthalmol Scand 79: 603-608, 2001.

60. Kwok LS and Coroneo MT: A model for pterygium formation. Cornea 13: 219-224, 1994

61. Dushku N, John MK, Schultz GS and Reid TW: Pterygia pathogenesis: corneal invasion by matrix metalloproteinase expressing altered limbal epithelial basal cells. Arch Ophthalmol 119: 695-706, 2001

62. Gallagher MJ, Giannoudis A, Herrington CS and Hiscott P: Human papillomavirus in pterygium. Br J Ophthalmol 85: 782-784, 2001

63. Piras F, Moore PS, Ugalde J, Perra MT, Scarpa A and Sirigu P: Detection of human papillomavirus DNA in pterygia from different geographical regions. Br J Ophthalmol 87: 864-866, 2003.

64. Di Girolamo N, McCluskey P, Lloyd A, Coroneo MT and Wakefield D: Expression of MMPs and TIMPs in human pterygia and cultured pterygium epithelial cells. Invest Ophthalmol Vis Sci 41: 671-679, 2000.

65. Barr RM, Walker SL, Tsang W, Harrison G, Ettehadi P, Greaves MW and Young AR: Suppressed alloantigen presentation, increased TNF-alpha, IL-1, IL-1RA, IL-10, and modulation of TNF-R in UV-irradiated human skin. J Invest Dermatol 112: 692-698, 1999

66. Nakamura $M$ and Nishida T: Differential effects of epidermal growth factor and interleukin 6 on corneal epithelial cells and vascular endothelial cells. Cornea 18: 452-458, 1999.

67. Nishida T, Nakamura M, Mishima $H$ and Otori T: Interleukin 6 promotes epithelial migration by a fibronectin-dependent mechanism. J Cell Physiol 153: 1-5, 1992.

68. Koch AE, Polverini PJ, Kunkel SL, Harlow LA, Di Pietro LA, Elner VM, Elner SG and Strieter RM: Interleukin-8 as a macrophage-derived mediator of angiogenesis. Science 258: 1798-1801, 1992.

69. Strieter RM, Kunkel SL, Elner VM, Martonyi CL, Koch AE, Polverini PJ and Elner SG: Interleukin-8. A corneal factor that induces neovascularization. Am J Pathol 141: 1279-1284, 1992.

70. Blaudschun R, Sunderkotter C, Brenneisen P, Hinrichs R, Peters T, Schneider L, Razi-Wolf Z, Hunzelmann N and Scharffetter-Kochanek K: Vascular endothelial growth factor causally contributes to the angiogenic response upon ultraviolet B irradiation in vivo. Br J Dermatol 146: 581-587, 2002.

71. Lee DH, Cho HJ, Kim JT, Choi JS and Joo CK: Expression of vascular endothelial growth factor and inducible nitric oxide synthase in pterygia. Cornea 20: 738-742, 2001. 
72. Andresen JL and Ehlers N: Chemotaxis of human keratocytes is increased by platelet-derived growth factor-BB, epidermal growth factor, transforming growth factor-alpha, acidic fibroblast growth factor, insulin-like growth factor-I, and transforming growth factor-beta. Curr Eye Res 17: 79-87, 1998.

73. Zolli CL: Experience with the avulsion technique in pterygium surgery. Ann Ophthalmol 11: 1569-1576, 1979.

74. Vorkas AP: Pterygium. Choice of operation. Trans Ophthalmol Soc 101: 192-194, 1981

75. De Ocampo G and Fojas MR: Studies on the bare sclera technique of pterygium operation. Philipp J Surg 15: 327-332, 1960.

76. Tomas T: Sliding flap of conjunctival limbus to prevent recurrence of pterygium. Refract Corneal Surg 8: 394-395, 1992.

77. Anduze AL: Conjunctival flaps for pterygium surgery. Ann Ophthalmol 38: 219-223, 2006.

78. Ang LP, Chua JL and Tan DT: Current concepts and techniques in pterygium treatment. Curr Opin Ophthalmol 18: 308-313, 2007.

79. Basti S and Rao SK: Current status of limbal conjunctival autograft. Curr Opin Ophthalmol 11: 224-232, 2000.

80. Memarzadeh F, Fahd AK, Shamie N and Chuck RS: Comparison of de-epithelialized amniotic membrane transplantation and conjunctival autograft after primary pterygium excision. Eye 22: 107-112, 2008.

81. Talu H, Tasindi E, Ciftci F and Yildiz TF: Excimer laser phototherapeutic keratectomy for recurrent pterygium. J Cataract Refract Surg 24: 1326-1332, 1998.

82. Walkow T, Daniel J, Meyer CH, Rodrigues EB and Mennel S: Long-term results after bare sclera pterygium resection with excimer smoothing and local application of mitomycin C. Cornea 24: $378-381,2005$.
83. Das S, Ramamurthy B and Sangwan VS: Deep lamellar keratoplasty for recurrent advanced pterygium. Ophthalmic Surg Lasers Imaging 40: 43-45, 2009.

84. Majmudar PA and Epstein RJ: Antimetabolites in ocular surface neoplasia. Curr Opin Ophthalmol 9: 35-39, 1998.

85. Mattox C: Glaucoma filtration surgery and antimetabolites. Ophthalmic Surg Lasers 26: 473-480, 1995.

86. Young AL, Tam PM, Leung GY, Cheng LL, Lam PT and Lam DS: Prospective study on the safety and efficacy of combined conjunctival rotational autograft with intraoperative $0.02 \%$ mitomycin $\mathrm{C}$ in primary pterygium excision. Cornea 28 : 166-169, 2009.

87. Gupta VP and Saxena T: Comparison of single-drop mitomycin C regime with other mitomycin $\mathrm{C}$ regimes in pterygium surgery. Indian J Ophthalmol 51: 59-65, 2003.

88. Akarsu C, Taner P and Ergin A: 5-Fluorouracil as chemoadjuvant for primary pterygium surgery: preliminary report. Cornea 22: 522-526, 2003.

89. Oguz H and Sobaci G: The use of hyperbaric oxygen therapy in ophthalmology. Surv Ophthalmol 53: 112-120, 2008.

90. Rosenthal JW: Beta-radiation therapy of pterygium. AMA Arch Ophthalmol 49: 17-23, 1953.

91. Wilson B: Beta irradiation of pterygia. Trans Ophthalmol Soc Aust 23: 96-100, 1963.

92. Kirwan JF, Constable PH, Murdoch IE and Khaw PT: Beta irradiation: new uses for an old treatment: a review. Eye 17: 207-215, 2003.

93. Emerson MV and Lauer AK: Emerging therapies for the treatment of neovascular age-related macular degeneration and diabetic macular edema. BioDrugs 21: 245-257, 2007. 